much is known of the origin of the nitrates in the soil from the results obtained by Warington at Rothamsted and by King in Wisconsin to allow one to suppose their amount would ever approximate to a constant even for the same soil, yet nitrates are perhaps the dominant factor in plant nutrition.

The phosphoric acid and potash figures are a little more in harmony, and we have examined those relating to the same four soils with the following results :-

Phosphoric acid. Parts per million

\begin{tabular}{|c|c|c|c|c|}
\hline & & Highest & Lowest & Mean \\
\hline $\begin{array}{l}\text { Windsor Sand } \\
\text { Norfolk Sand } \\
\text { Leonardtown Loam } \\
\text { Sassafras Loam }\end{array}$ & \begin{tabular}{l|}
$\cdots$ \\
$\cdots$ \\
$\cdots$ \\
$\cdots$
\end{tabular} & $\begin{array}{l}12 \cdot 88 \\
16 \cdot 52 \\
16 \cdot 5 \\
21 \cdot 45\end{array}$ & $\begin{array}{l}2 \cdot 65 \\
1 \cdot 71 \\
2 \cdot 9 \\
2 \cdot 24\end{array}$ & $\begin{array}{l}6.21 \pm 0.25 \\
6.33 \pm 0.19 \\
7.16 \pm 0.26 \\
7.61 \pm 0.30\end{array}$ \\
\hline
\end{tabular}

\begin{tabular}{|c|c|c|c|c|}
\hline & & \multicolumn{3}{|c|}{ Potassium. Parts per million } \\
\hline & & Highest & Lowest & Mean \\
\hline $\begin{array}{l}\text { Windsor Sand } \quad . . \\
\text { Norfolk Sand } \ldots \\
\text { Leonardiown Loam } \\
\text { Sassafras Loam ... }\end{array}$ & $\begin{array}{l}\cdots \\
\cdots \\
\cdots \\
\cdots\end{array}$ & $\begin{array}{l}46 \cdot I I \\
44 \cdot 9 \\
51 \cdot 66 \\
46 \cdot 8\end{array}$ & $\begin{array}{r}10.90 \\
11.64 \\
10.08 \\
7.94\end{array}$ & $\begin{array}{l}24.27 \pm 1.02 \\
22.19 \pm 0.49 \\
23.61 \pm 0.65 \\
24.22 \pm 0.63\end{array}$ \\
\hline
\end{tabular}

These numbers would indicate variation round a mean which is practically the same for all soils as regards potash, but which as regards phosphoric acid has a different value for different types of soil, approaching one value for sands and another for loams. This agrees with the probability that the potash compounds are of the same type in all soils, whereas several distinct compounds of phosphoric acid must exist in relative proportions varying with the type of soil, and we surmise that these mean results might be correlated with the amount and solubility of the compounds appropriate to the various types of soil were more data available. But for the purpose of the argument we are not concerned with mean results, but with individual soils; the authors rest their case on the constancy of composition of the soil solution, and their own figures show variations too wide and too numerous to fall within any allowable limits. It may be true : enough that the variations exhibited cannot be correlated with the known productiveness of the soils, but that is only a proof of the ineffectiveness of the analysis of the aqueous extract of a soil, not of the non-existence of a chemical soil factor in crop production. Indeed, it is not quite easy to see what the numbers do represent; the volume of water employed is so small, and the time of extraction so short, that they cannot stand either for the solution existing in the soil or for the material which water could extract during the growth of a crop. Some analyses are given of the actual solution extracted from various soils; all that can be said of them here is. that they show no more constancy of composition than the laboratory extracts, nor do the old analyses of the drainage waters at Rothamsted lend any more support to the idea of a soil solution of constant composition.

Though Dr. Whitney's main argument is thus hardly tenable on his own showing, certain side issues are worth a little notice. Dealing with the action of fertilisers, he notices that, while the wheat crop on the best fertilised plot at Rothamsted averages about 33 bushels, on the plot which has been unmanured for sixty years it has fallen to 12 or $I_{3}$ bushels. Yet on the similarly unmanured plot in the Agdell field, where No. I777, vOL. 69] the wheat is grown once every four years in rotation with roots, barley, and clover or fallow, but little falling off is apparent. Hence he concludes that, in virtue of the rotation, the fertility of the Agdell field is unimpaired, whereas in the continuous wheat field " the decrease can be ascribed only to some physical change in the soil, to some chemical change other than. the actual loss of plant food taken up by the crops." But when any other crop on the unmanured plots in Agdell field is considered, the decline in fertility is. enormous; roots and clover only yield minimal crops; so far as they are concerned the cultivation of the soil involved in the rotation has been quite unable to maintain the fertility. The wheat, with its powerful root system, holds up better, but its production is falling. steadily; it is important to see how long it will be maintained, 'though it need never be expected to fall to the level of the continuous wheat, because the land is practically only cropped every other year, so trifling has the output of roots become.

When Dr. Whitney says that there are few instances showing that a given fertiliser is required by a certain soil, and that generally fertilisers have no consistent or continuous effect, he ignores too much the results. both of experiment and experience in countries like our own. In England a body of knowledge has been accumulated concerning the requirements of particular soils and crops for specific fertilisers such as is hardly possible in America, where much of the land has only recently been brought under intensive cultivation involving the use of purchased manures.

In another place Dr. Whitney says " the beneficial effect of fallowing is not due to an accumulation of soluble plant food in the soil." Not wholly due, perhaps, but King's investigations show what a powerful factor the accumulated nitrates become, and a recent discussion of the Rothamsted results shows that after a wet autumn, to wash out the nitrates formed during the summer fallow, the benefit of fallowing disappears almost entirely, whereas after a dry autumn and early winter it produces an increase of crop of nearly 50 per cent.

Suggestive as Dr. Whitney's memoir must be to all agricultural chemists, we thus do not consider that the main theory it propounds possesses any permanent value. We should be sorry if we have failed to appreciate the argument properly, but it is not always easy to follow, the text being somewhat deficient in sequence and orderly arrangement; indeed, we are disposed to think that had the question been set out a little more nakedly at the outset, and the demonstration marshalled with more precision, a somewhat different conclusion would have been reached by the authors. The fundamental thesis is unimpeachable, that water content and temperature are the main factors in crop production, but the chemical composition of the soil is also a large factor, though its magnitude and relation to the other physical factors do not yet admit of complete determination.

A. D. $\mathrm{H}$.

\section{THE SURVEY OF INDIA.}

A VOLUME of extracts from narrative reports of the Survey of India for the season Igoo-Igor ${ }^{2}$ has recently been issued. These extracts, which used to be published in the same volume as the annual report, are now issued separately. The reports selected for publication show admirably the range of the operations of the Survey of India. They deal with seven subjects.

(I) Zincography.-For certain classes of maps reproduction from zinc is eminently suitable, and owing to the introduction of thin zinc plates, difficulties of

I Pp. 68. (Calcutta : Government Printing Office, 1903) Price 2s: $3 d$. 
storage have largely disappeared. For the rapid reproduction of maps photozincography was, until a few years ago, the method invariably used. Two new methods have now superseded photozincography; one of these, "heliozincography," was worked out by the Ordnance Survey, and subsequently adopted by the Survey of India ; the other, the "Vandyke process," was invented by Mr. Vandyke, of the Survey of India, and has now been adopted by the Ordnance Survey. The first method consists in reproduction direct on a sensitised zinc plate in contact with a reversed negative. The Vandyke process consists in reproduction direct on a sensitised zinc plate in contact with the original drawing. Lately, at Southampton, it has been even found possible to reproduce maps drawn on thick drawing paper. The process has been patented by $\mathrm{Mr}$. Vandyke, and is a cheap and very efficient means of reproducing cadastral maps.

(2) Geodetic Triangulation in Burma.-The principal point to note is the determination of the coefficient of terrestrial refraction by night as well as by day, the coefficient being the absolute refraction divided by the terrestrial arc. By day (from observations to helio stats between noon and 3 p.m.), the coefficient was 0.072 ; by night (from observations to lamps), 0.083 . It is possible that if the night observations had been taken from midnight onwards the coefficient would have been smaller.

Some interesting secondary triangulation (the Manipur series) was also carried out, one of the rays being 95 miles long.

(3) Latitude Operations. - The average probable error of 14 latitudes observed with a zenith telescope was $\pm 0^{\prime \prime} .063$, or say six and a half feet. India is, of course, committed to the system of refined latitudes, and comparatively few of them.

(4) Experiments with the Jäderin Base Apparatus.A base was measured at Dehra Dun with the following results :-

$$
\begin{array}{lllll}
\text { By Jäderin apparatus... } & \ldots & 39,187.272 & \text { feet } \\
\text { By Colby's bars } & \ldots & \ldots & 39,187.462 \quad,
\end{array}
$$

a discrepancy of $1 / 194,000$.

It was found that the $80 \mathrm{ft}$. wire was the most convenient, and various practical suggestions are made o.1 the use of the apparatus. It was apparently in contemplation to measure a Jäderin base in Burma. There would appear to be no doubt as to the gain in speed, and also no doubt that it is possible under suitable conditions to do away with base-line figures by the use of, say, ${ }_{5} 5$ mile bases.

(5) Magnetic Survey of India.-This has been commenced, and there are now five base stations, Calcutta, Bombay, Rangoon, Dehra Dun, and Kodaikanal. It was intended in $x 901$ to send out three field detachments to work in an area west of a line joining Dehra Dun and Bombay, two to work along railway lines, and $a$ third, in the desert.

(6) Tidal and Levelling Operations.-Tidal observations have been, or are being, taken at forty-one ports in, and adjacent to, the Indian Empire. Tables are given of the tidal constants at various ports deduced from the rgoo observations. As regards the accuracy of prediction, at fourteen open coast stations during Igoo it was found that the mean error of prediction of the time of high or low water was thirteen minutes, and the average error of predicted heights was one twenty-fifth of the range.

The tide-predicting machine belonging to the Indian Government (due, it is believed, to Lord Kelvin and Mr. Roberts) is in London, and the Survey of India sends home annually the latest values of the tidal constants to Mr. Roberts, who sets the instrument for the port in question, and causes it to describe graphically the tide curve for any future year required. As Prof. Darwin has remarked in his book on "The Tides," it is characteristic of England that this admirable machine has not been made use of for any of the home ports.

(7) Topographical Surveys.-The seventh report deals with some details of one-inch work in Burma, and incidentally serves to emphasise the necessity of keeping cadastral and topographical work distinct. The topographical surveys are fully described in the annual report, the most interesting being the survey on a scale of half inch to one mile of 17,000 square miles carried out in China during the expedition.

When shall we have an Imperial Survey capable o doing for the Crown colonies, protectorates and occupied territories what the Survey of India does for India?

C. F. C.

\section{ISAAC COOKE THOMPSON.}

IVERPOOL has lost a well-known naturalist in L the death of Mr. I. C. Thompson, who was hon. treasurer of the Liverpool Marine Biology Committee from its foundation nearly twenty years ago. He had a wide knowledge of the Crustacea, and especially of Copepoda, the group upon which most of his original work was done, but he was also a keen field-naturalist, interested in the lives and habits of his animals, and preferring to catch the specimens himself and to examine them in the first place alive. He was always a prominent member of the party during the dredging expeditions in the Irish Sea and at the Port Erin Biological Station. Little more than a month before his death he was one of the leaders in the British Association dredging excursion which followed the Southport meeting.

Thompson's early papers on the Copepoda dealt with the forms found in Liverpool Bay and other parts of the Irish Sea, but he collected wherever he went, and, as the result of vacation travels, published papers on the Mediterranean and Norwegian species and on collections from Madeira, the Canaries, the west coast of Ireland, the Færöe Channel, and a traverse through the North Atlantic to Quebec. He also described Copepoda from the Bay of Bengal, the Antarctic, the Red Sea and east coast of Africa, and recently from the Oceana Expedition in the North Atlantic. In these papers he described many new forms, aided in the elucidation of not a few obscure points, and greatly extended our knowledge of the geographical distribution of the group. Thompson's last piece of scientific work was a large report, undertaken jointly with Mr. Andrew Scott, upon the Copepoda of the Ceylon pearl banks, recording more than 280 species, of which 76 are described as new to science. This extensive work was completed some weeks ago, and Thompson passed the last of his sheets for press shortly before he was struck down; it has been referred to by one who saw the proofs as the pioneer work on tropical Harpacticidæ and Licho molgidæ. Thompson's papers have been published for the most part in the Transactions of the Liverpool. Biological Society, the Journal of the Linnean Society, the Annals and Magazine of Natural History, and the reports of the British Association. He was in correspondence with Claus, Richard, Giesbrecht, and other Continental workers, and frequently supplied them with British specimens required for comparison or description in their monographs.

There were few of the local organisations in Liverpool for the advancement of science and the applications of scientific teaching in which Mr. Isaac Thompson did not play a prominent part, and his posi-

No. I 777 , voL. 69] 